\title{
RESTITUIÇÃO DE ACERVOS ARQUEOLÓGICOS: NOVAS SOLUÇÕES OU ANTIGOS PROBLEMAS?
}

\author{
Renata de Godoy ${ }^{1}$ \\ Emilly Cristine Barbosa dos Santos ${ }^{2}$
}

\section{RESUMO}

As reservas técnicas arqueológicas no Brasil hoje precisam ser repensadas, seja em virtude de seu colapso seja em função da necessária inserção social preconizada tanto na arqueologia quanto na museologia. Entendemos que é o momento de propor novas soluções para salvaguarda e exposição de acervos arqueológicos, e que diferentes estratégias de colaboração com diversos públicos a respeito do gerenciamento de seus patrimônios arqueológicos é um caminho possível. $O$ artigo apresenta uma discussão teórica sobre repatriação e restituição de coleções arqueológicas, e propõe refletir sobre o tema. Para tanto, trazemos como exemplo um estudo de caso bastante singular: a proposta de criação do primeiro museu arqueológico do Distrito Federal.

PALAVRAS-CHAVE: restituição, repatriação, colaboração, museu arqueológico, Distrito Federal.

\section{ABSTRACT}

Reassessing archaeological technical reserves in Brazil today is a major goal, either because of their collapse or because of the necessary social insertion advocated in both archeology and museology. We understand that it is time to propose new solutions for the safeguarding and exhibition of archaeological collections, and that different strategies of collaboration with various audiences regarding the management of their archaeological heritages is a possible solution. The article presents a theoretical discussion about repatriation and restitution of archaeological collections, and proposes to reflect on the theme. To this end, we bring as an example a very singular case study: the proposal to create the first archaeological museum of the Federal District.

KEYWORDS: restitution, repatriation, collaboration, archaeological museum, Federal District.

\footnotetext{
1 Professora adjunta da Universidade Federal do Pará, Programa de Pós-Graduação em Antropologia da, Brasil (UFPA/PPGA). Arquiteta e Urbanista, Mestre em Gestão do Patrimônio Cultural (PUC-GO) e PhD em Antropologia/Arqueologia (Universidade da Flórida). E-mail: godoy@ufpa.br.

${ }^{2}$ Mestranda da Universidade Federal do Pará, Programa de Pós-Graduação em Antropologia da, Brasil (UFPA/PPGA). Museóloga e Especialista em Planejamento e Gestão Pública do Patrimônio Cultural (UFPA).E-mail: emilly.cris.santos@gmail.com.
} 


\section{RESUMEN}

Las reservas técnicas arqueológicas en Brasil hoy necesitan ser repensadas, sea en virtud de su colapso sea en función de la necesaria inserción social preconizada tanto en la arqueología y en la museología. Entendemos que es el momento de proponer nuevas soluciones para la salvaguardia y exposición de acervos arqueológicos, y que diferentes estrategias de colaboración con diversos públicos acerca de la gestión de sus patrimonios arqueológicos es un camino posible. El artículo presenta una discusión teórica sobre repatriación y restitución de colecciones arqueológicas, y propone reflexionar sobre el tema. Para ello, traemos como ejemplo un estudio de caso bastante singular: la propuesta de creación del primer museo arqueológico del Distrito Federal.

PALABRAS CLAVE: restitución, repatriación, colaboración, museo arqueológico, Distrito Federal.

\section{INTRODUÇÃO}

Vivemos uma crise nos acervos arqueológicos. No Brasil, a crise acentuou-se nos últimos anos. A imensa demanda derivada da arqueologia empresarial tem esbarrado na velocidade infinitamente inferior de crescimento das reservas técnicas. É uma crise que precisa de soluções de negociação complexa e certamente sem uma unanimidade prevista no prazo ideal. Em contrapartida, a museologia também experimenta um momento de ampliação de conceitos e formas de atuação mais inclusivas e socialmente relevantes.

Nesse cenário, ainda debatemos termos de cooperação para restituição de coleções arqueológicas, e em nível internacional repatriação de bens materiais que na maioria das vezes nunca chegam ao consenso. No país, não têm sido raros os casos de comunidades, instituições locais, indivíduos e populações tradicionais questionarem e requererem acesso, gestão e retorno de coleções escavadas, seja em projetos de mitigação, seja em projetos acadêmicos. É o momento de admitirmos soberania, que apesar de ser respeitada não tem uma solução simples. Este artigo apresenta uma discussão teórica sobre formas de colaboração, apresentando uma discussão pontual sobre repatriação e restituição como uma estratégia de inserção social e de possível resolução para o problema atual do saturamento das reservas técnicas e relatando um estudo de caso singular para tal reflexão. Não temos a intenção de propor soluções imediatas, mas de incentivar uma reflexão profunda sobre este tema que permeia a prática arqueológica, quer queiramos ou não. 


\section{MUSEUS DEMOCRÁTICOS: REPENSANDO O LUGAR DOS BENS CULTURAIS}

Pensar o museu de hoje é uma tarefa bem mais complexa do que pensar o museu de antigamente. Foi a partir da segunda metade do século $X X$ que as instituições museológicas começaram a repensar sua função social, buscando ser relevantes para os debates atuais. Com isso, elas deixam de se preocupar com o objeto em si e se voltam para os grupos sociais nos quais estes objetos foram criados.

Nesse prisma, os museus de hoje têm se transformado cada vez mais em espaços a serviço da sociedade, buscando compreender os anseios e questionamentos da comunidade na qual eles estão inseridos. A partir da década de 1980, em consonância com as discussões dos conceitos de participação e empoderamento social, essas instituições começaram a desenvolver um processo de democratização mais abertamente. Em consequência, não cabe mais tratar o público como mero contemplador ou visitante, atualmente, ele é compreendido como colaborador do fazer museológico, sendo participante ativo de desenvolvimento sociocultural e da interpretação e gestão dos bens culturais.

Falamos de um público mais consciente de seus direitos no século XXI, e a cada dia mais interessado em gerenciar sua própria cultura material. Não é mais novidade a demanda incisiva de manutenção de coleções em seus locais de origem, assunto que direciona a discussão sobre criação de novos museus e mais ainda sobre novas tipologias de acervo e exposição museológicas. Por meio do estudo de caso apresentado a seguir, propomos repensar o esgotamento atual das reservas técnicas no Brasil e, assim, refletir sobre a restituição de coleções. A discussão sobre restituição de bens arqueológicos pode se inserir nesse novo cenário dos museus, que embora tenha passado por uma importante mudança de paradigma, assim como a Arqueologia, ainda mantêm práticas seculares de aquisição e guarda de objetos.

Falar sobre restituição no Brasil assemelha-se às discussões sobre repatriação em nível internacional. As principais justificativas que impedem a restituição dos artefatos é a alegação de que as sociedades colonizadas não têm condições de conservação para a manutenção dos objetos no local de origem. É afirmado, ainda, que esses artefatos, enquanto patrimônios da humanidade, devem estar expostos em museus universais, de modo a garantir o acesso universal, posto que não atendem somente à cultura nacional ou regional, mas a toda humanidade (FERREIRA, 2014). Cabe questionar, então: a quem pertencem os artefatos? Quem tem o direito de gestão e interpretação sobre eles? Esta justificava de preservação e acessibilidade do patrimônio é uma concepção paternalista, 
que não encontra ressonância nas diferentes formas de apropriação de bens culturais de sociedades não ocidentalizadas.

As reservas técnicas de museus estão cada vez mais sobrecarregadas de objetos adquiridos de coletas sistemáticas ou doações. No caso das coleções arqueológicas brasileiras, crescentemente vêm acumulando milhares de artefatos resultantes dos inúmeros projetos de desenvolvimento nacional. Nesse sentido, é essencial pensar em novos processos de musealização por meio da gestão compartilhada entre a comunidade e o museu, a partir dos quais os sujeitos possam ter maior poder de decisão sobre a preservação do próprio patrimônio, considerando as tradições e modos de compreender o mundo da comunidade.

Baseada em um estudo de caso relacionado à pesquisa de doutorado da primeira autora, propomos a seguir uma reflexão sobre estratégias ligadas à agência e política locais que visaram à construção de caminhos institucionais para a criação de um museu arqueológico no Distrito Federal. Neste exemplo, a restituição do acervo arqueológico seria a maior demanda, mas não se trata de uma comunidade clássica nem mesmo de um público que poderíamos classificar como descendente nos padrões tradicionais.

\section{PESQUISA COLABORATIVA EM ARQUEOLOGIA}

A ciência que se desenvolveu a partir do século XIX adquiriu um caráter racional e essencialista e foi institucionalizada como conhecimento hegemônico e tomada como um modelo autoritário. O fazer científico, visto como universal, neutro, pronto e acabado, tornou-se instrumento para a dominação política. A ciência desenvolveu-se enquanto instituição autônoma com finalidade de propiciar o crescimento econômico e o progresso social.

Saladino (2014) afirma que no caso da institucionalização da Arqueologia no Brasil suas ações foram baseadas em uma "agenda desenvolvimentista", com perspectiva imperialista. De acordo com Andrade Lima (2007), a Arqueologia adquiriu a missão de construir narrativas históricas da origem de formação de uma nação, de modo a legitimar o poder dominante a partir de um discurso nacionalista. A imagem da Arqueologia brasileira está vinculada ao paternalismo e à hierarquização, causando um distanciamento da realidade social (SALADINO, 2014).

No entanto, na pós-modernidade os questionamentos sobre a construção de uma ciência enquanto uma instituição voltada ao desenvolvimento da sociedade têm se tornado cada vez mais crescentes. Leite (1993) afirma que na década de 1960 a América Latina começa a criticar a produção científica dependente de países centrais desenvolvidos e 
busca sinalizar para uma produção local. Sob tal cenário, a sociedade é levada a repensar o paradigma científico hegemônico, com a finalidade de construir uma ciência mais autônoma e independente, cujo propósito esteja alicerçado no desenvolvimento e na mudança social.

É nas discussões pós-coloniais que mais efetivamente são criticadas as práticas arqueológicas realizadas para o projeto de expansão do colonialismo e imperialismo entre os séculos XV e XX pela Europa Ocidental (LIEBMAN, 2008). Essas discussões estão voltadas à potencialização da análise e interpretação crítica dos estudos arqueológicos, de modo a envolver a comunidade nesse processo de investigação sobre o passado de povos colonizados e subjugados.

Ao longo da institucionalização desta disciplina, não foi desenvolvida uma discussão substancial sobre as intenções e implicações da prática arqueológica, estando voltada, sobretudo, para questões técnicas de coleta, registro e análise. O fazer arqueológico distante e despreocupado com os interesses da sociedade e as consequências na realidade social implica na indiferença do público que não se percebe neste processo científico (MERRIMAN, 2004). Isso acarretou na depreciação e subjugação de outras formas de saberes frente ao conhecimento científico e também reverberou na desconfiança e na indiferença do público frente ao fazer científico. Conforme Atalay (2010), tal situação é evidente na realidade dos povos indígenas, que têm vestígios de ancestrais analisados e preservados por pesquisadores, cuja interpretação é baseada na visão da ciência ocidental em detrimento à tradição da história oral.

Essa abordagem implica na falta de relevância do trabalho da Arqueologia para o público não arqueólogo. A maioria dos projetos de Arqueologia no Brasil é realizada em um curto período de tempo, pelo fato de ainda estar ligada à agenda do mercado, direcionada para uma numerosa quantidade de empreendimentos desenvolvimentista de infraestrutura. Muitas pesquisas ainda seguem postulados antiquados que se resumem na realização do trabalho de escavação e coleta para análise em laboratório, sem sequer estabelecer um contato mínimo com a comunidade do entorno.

Isso reflete principalmente na destruição de sítios arqueológicos e pilhagem de artefatos, posto que estes, muitas vezes, são vistos pelas pessoas como insignificantes. Um exemplo está no trabalho de Green, Green e Neves (2011) com o grupo indígena Palikur, que identificou em pesquisas de história oral anteriores que vários sítios da região foram depredados, devido à procura de artefatos para venda e também pelo entendimento de inutilidade e desvalorização de alguns artefatos que foram destruídos.

$\mathrm{Na}$ realidade, os interesses da maioria do público não estão relacionados ao passado e tampouco aos artefatos arqueológicos, sobretudo em comunidades que estão 
preocupadas com a proteção do território ou com a garantia do alimento e não estabelecem uma correlação com essas lutas. Isto se constitui um dos maiores desafios para Arqueologia, cuja produção de pesquisa deve ter ressonância e interesse local (GREEN, GREEN e NEVES 2011).

O arqueólogo deve perceber a importância de se engajar com as questões sociais que permeiam seu campo. Atalay (2010) propõe questões fundamentais para o desenvolvimento do trabalho da Arqueologia: de que forma a pesquisa arqueológica é relevante para a sociedade? Quem tem acesso a ela? Quem é beneficiado e de que forma? Para a compreensão dessas questões-chave para o trabalho do arqueólogo, é essencial a realização de pesquisas voltadas ao entendimento do público, de modo a estabelecer um canal de comunicação eficaz. No entanto, de acordo com Merriman (2004), embora seja fundamental ter o panorama das diversidades de audiências e de construção dos significados sobre os recursos arqueológicos de modo a evitar que a Arqueologia seja percebida como irrelevante, este tipo de pesquisa foi pouco desenvolvido ao longo da história desta disciplina.

Mais recentemente, percebe-se o envolvimento de arqueólogos com comunidades interessadas, transformando o próprio fazer arqueológico (SUPERNANT, 2012). Cabe lembrar que o fazer científico pós-moderno não está mais limitado em uma resolução universal, desse modo, ele busca considerar os contextos sociais, culturais, políticos e históricos da sociedade, para potencializar o papel social da ciência. Para esse propósito, a produção científica demanda um entrelaçamento entre os saberes e práticas científicas e tradicionais (SANTOS, 2005), promovendo a colaboração entre pesquisador e comunidade, como no caso da gradual construção da relação entre arqueólogo e público. A Arqueologia pode adquirir relevância para a sociedade em geral na medida em que ela esteja engajada com as demandas apresentadas pelo público e ao mesmo tempo promova a participação ativa do público não arqueólogo no processo de pesquisa e preservação arqueológica.

Para Atalay (2010), a pesquisa participativa de base comunitária deve assumir como principal propósito beneficiar a sociedade. Para tanto, a metodologia deve estar fundamentada no envolvimento com grupos comunitários no processo de produção do conhecimento. Conforme a autora, a denominada Pesquisa Participativa de Base Comunitária tem como intuito realizar ações para promover o desenvolvimento de projetos dirigidos pela comunidade e para o interesse desta. Por isso, essas ações buscam envolver a comunidade diretamente no processo da pesquisa, no sentido de estabelecer uma parceria entre pesquisador e moradores. 
Destacam-se duas questões-chave propostas por Supernant (2012) para pesquisas arqueológicas colaborativas. A primeira concerne à comunicação, voltada à construção da confiança e mudança de percepção sobre os propósitos e práticas arqueológicas; e a segunda está alicerçada na educação direcionada para o compartilhamento do conhecimento entre os membros da comunidade, bem como para a mudança de percepção sobre a noção de patrimônio.

Para tal fim, o trabalho colaborativo em Arqueologia tem de reconhecer os sujeitos da comunidade também como produtores de conhecimento, para então tomar o processo de construção da pesquisa como uma rede de relações colaborativas, cujos saberes arqueológicos e tradicionais estejam em interação. Para Atalay (2006), a prática da Arqueologia em territórios indígenas que não considere um olhar crítico da colaboração, da epistemologia dos povos estudados e das concepções nativas sobre passado e tempo, assim como a negligência com o papel da pesquisa, estará replicando o paradigma arqueológico clássico, cujas premissas ancoram-se em métodos convencionais de uma ciência acrítica, reproduzindo a perspectiva imperialista.

Portanto, no trabalho arqueológico o público participa, conjuntamente com a equipe de pesquisa, desde o planejamento da pesquisa, incluindo a tarefa de escavação e coleta, assim como na análise de dados e publicação dos resultados. A partir desse processo, potencializa-se a aproximação entre a Arqueologia e o público, bem como o reconhecimento do saber empírico pertencente a grupos sociais. Como afirma Santos (2005, p. 146): "construir uma 'ciência para as pessoas' implica fertilizar o saber científico com outros saberes, derrubar os obstáculos epistemológicos que impedem a construção de um novo objecto do saber e a sua necessária interacção com o sujeito".

\section{PESQUISA ARQUEOLÓGICA E PARTICIPAÇÃO PÚBLICA}

Cabe ressaltar primordialmente que o entendimento de público, no âmbito da Arqueologia, refere-se a uma gama diversificada de grupos sociais que apresentam percepções de realidade e interesses bastante divergentes. De acordo com Merriman (2004, p. 122), o público é "um conjunto inconstante de grupos com interesses transversais que muitas vezes possuem afinidades".

Entende-se que o público da Arqueologia abrange tanto não especialistas quanto profissionais da área, os quais compartilham o interesse pelo trabalho arqueológico. Os arqueólogos compõem também a diversificada gama de público, posto que eles constituem um grupo que compartilham opiniões e experiências profissionais, estando em um 
constante processo comunicação com os demais públicos. A prática destes profissionais assegura que grupos historicamente privados de direitos possam contestar seus direitos a partir do registro contextual de informações sobre os vestígios dos ancestrais. Isto posto, ressalta-se a importância de romper com a visão dominante do pesquisador no desenvolvimento da investigação, tornando-se essencial, em consonância com Merriman (2004), inserir a comunidade no fazer arqueológico, no sentido de que esta construa a própria forma de entender o passado.

Os projetos arqueológicos devem considerar os diversos interesses, compreendendo que as comunidades são complexas e que nelas se estabelecem relações fluidas, cujos sujeitos pertencem a diferentes grupos sociais, e estes, por seu turno, têm membros com perspectivas, necessidades e expectativas divergentes (ATALAY, 2010). Nesse sentido, Green, Green e Neves (2011) atentam para o fato de que o empoderamento não é neutro e descontextualizado, e sendo assim, uma comunidade inteira não pode se empoderar completamente, alguns membros terão maior liderança do que outros.

Atalay (2010) observa que a abordagem de pesquisa colaborativa enfrenta vários desafios no contexto da pós-modernidade, dentre eles estão: determinar a parceria colaborativa apropriada em cada comunidade; trabalhar com grupos diversos dentro de cada comunidade, os quais têm diferentes intenções e garantir o direito de propriedade intelectual. Em razão disso, segundo a autora, os projetos de pesquisa colaborativa em Arqueologia devem estabelecer parcerias com a comunidade a fim de identificar conjuntamente as necessidades e interesses do grupo, para então propor pesquisas colaborativas. Considerando todas essas tipologias de público, o trabalho colaborativo tem potencial de produzir múltiplas formas de abordagens a partir de uma comunicação horizontal entre diferentes linguagens, articulando conhecimentos científicos e locais, de modo que a ação se torne relevante para a prática sociocultural do grupo engajado.

Igualmente, a incorporação da equipe de arqueólogos na comunidade causa confrontos entre pesquisadores e moradores locais. Atalay (2010) percebe que além de buscar estabelecer parceria com os membros da comunidade, é fundamental compreender como eles percebem o pesquisador, a intenção e o papel deste na realidade das pessoas que vivem na área de estudo. A autora relata que há um desiquilíbrio de poder entre arqueólogos e moradores, no sentido de em que grande parte dos casos as pessoas não conhecem o campo da Arqueologia, sendo preciso introduzir discussões básicas sobre conhecimento arqueológico. Devido a isso é necessário um contato preliminar para dialogar com o público e informar sobre os objetivos da pesquisa, esta é a etapa imprescindível para 
a construção de confiança e parceria entre dois públicos distintos (pesquisador e comunidade).

O projeto de pesquisa colaborativa com o intuito de contribuir para o processo de transformação social da comunidade precisa desenvolver ações para além de atividades educativas-informativas, com a finalidade de engendrar a construção de conhecimento mais amplo, relacionado à tradição oral. Em consequência, isso promove, de fato, a mudança de perspectivas e de formas de preservação do patrimônio arqueológico (GREEN, GREEN E NEVES, 2011).

Cabe enfatizar que os projetos de pesquisa colaborativa não apresentam um postulado pronto e definitivo. Como afirma Atalay (2006), cada realidade requer estratégias próprias, pelas quais torna possível aos grupos sociais a interpretação, bem como apropriação e gestão do próprio bem cultural. As trocas de experiências entre pesquisadores e comunidade faz emergir novas demandas de pesquisa, as quais podem engendrar a descentralização da teoria e prática do próprio campo da Arqueologia, construindo outras formas de produção desta ciência.

\section{MUSEU ARQUEOLÓGICO E O SONHO POSSÍVEL ${ }^{3}$}

Meu primeiro contato com o complexo arqueológico localizado entre as cidadessatélites Taguatinga, Ceilândia e Samambaia, no Distrito Federal, foi em 2004. Era mais um proposta no âmbito da arqueologia empresarial, relativa a um projeto de infraestrutura embargado por denúncia local e em virtude do patrimônio arqueológico (BARBOSA e COSTA, 2005). Começava ali um longo relacionamento que tive com este lugar, e com pessoas de lá, que, por diversas razões, importavam-se com um passado muito distante de todos nós (GODOY, 2012).

Estou falando de sítios do tipo oficina lítica, vestígios paleolíticos que hoje dividem espaço com uma metrópole populosa e heterogênea. São sítios de difícil identificação, quase invisíveis na paisagem não fossem os afloramentos de quartzito com retiradas que permitem perceber sua presença para olhos treinados, e de uma coleção impressionante de vestígios líticos que incluem instrumentos plano-convexos, que chamaremos aqui de lesmas, e uma ponta de projétil de quartzo hialino que brilha aos olhos de leigos e especialistas pela sua significância arqueológica, e mais ainda pela sua estética facilmente reconhecível e unanimemente admirável. Em contrapartida, estamos realmente lidando com

\footnotetext{
${ }^{3}$ Subitem descrito em primeira pessoa por Renata de Godoy.
}

\begin{tabular}{|l|l|l|l|l|l|l}
\hline (C) Rev. Arqueologia Pública & Campinas, SP & v.11 & n.2 & p. 106 & Novembro/2017 & ISSN 2237-8294
\end{tabular}


uma coleção lítica que tem como apelo mais relevante a presença de instrumentos que não apresentam um óbvio potencial estético, mas inquestionável significância arqueológica.

[...] Instrumentos do tipo plano convexo, tradicionalmente
denominados de "lesmas", as quais são consideradas tão
singulares no Brasil Central a ponto de, no passado, serem
indicativos de marcadores culturais, relacionados a ocupações
pretéritas vinculadas a Tradição Itaparica. (VIANA, 2011, p. 101 e
102)

A execução de pesquisas arqueológicas naquele lugar tem sido pontual e significativa e congregou equipes diferentes ao longo de mais de 20 anos de investigações quase sempre pautadas em mitigação de impacto em função de obras de infraestrutura. Eurico Miller, no início dos anos 1990 (MILLER, 1993), Emílio Fogaça e Lúcia Juliani, a convite do IPHAN, alguns anos depois (FOGAÇA e JULIANI, 1997), a minha equipe, coordenada por Mariza Barbosa e Diogo Costa, entre 2004 e 2005 (BARBOSA e COSTA, 2005), Fogaça novamente, desta vez em parceria com Paulo Jobim em seguida (MELLO e FOGAÇA, 2007), entre outros que chegaram depois que finalizei meu levantamento de dados, em 2008 (TELLES e CASTRO, 2010).

A presença dos arqueólogos transformou a visibilidade dos sítios e ajudou no processo de ressignificação da cultura material associada ao vestígio paleoíndio em Brasília. Quando tive o privilégio de coordenar a chamada equipe de gestão do projeto encabeçado por Barbosa e Costa em 2004, minha hipótese era a dificuldade em sensibilizar os moradores do entorno quanto à importância daquele bem cultural. Logo percebi que aquele público, apesar de extremamente heterogêneo, tinha uma demanda ainda que retórica comum: todos queriam que aquela coleção permanecesse no Distrito Federal. Utilizando estratégias diferenciadas para abordagem do público, considero os resultados mais importantes nesse assunto àqueles gerados por dois grupos focais que conduzimos com atores selecionados em Samambaia e em Ceilândia. Todos concordaram com o retorno das coleções, e todos demandavam a criação de um espaço para exposição (GODOY, 2005). Estavam defendendo a criação de um museu arqueológico.

A partir dessa resposta extremamente positiva, propus-me a entender o porquê de tal reivindicação pública em um projeto de doutorado em Antropologia nos Estados Unidos. Estamos falando de uma unidade federativa com instituições respeitáveis de ensino, pesquisa e extensão, mas que não agregam pesquisadores, laboratórios e nem exposições museológicas na área da Arqueologia, e de uma população formada por migrantes, há meio século construindo novas identidades e formas de apego territoriais. Eu me deparava com extremos o tempo todo: recente e antigo; rural e urbano; urbanização e preservação 
Revista de Arqueologia Pública

ambiental; fantasia e realidade. O maior dos contrastes, no entanto, é um com o qual nos deparamos frequentemente quando tratamos de patrimônio cultural: discurso e prática. $O$ potencial gerador de conflitos nesse cenário é eminente, ao mesmo tempo em que a colaboração soa como utopia em se tratando de uma população imensa (mais de um milhão de habitantes no entorno dos sítios, mais de três milhões em todo o Distrito Federal).

Em 2008, três anos depois, em meio aos interlocutores que me propiciaram entender os vínculos construídos entre o presente e o passado pré-colonial em Brasília, conheci alguém disposto a mover céus e terra para a criação do primeiro museu arqueológico do Distrito Federal. Em maio 2014, 10 anos depois da minha primeira visita, recebi o convite de lançamento do "Museu Arqueológico e Histórico do Planalto Central", que encerraria um vazio institucional, pois de acordo com o autor da mensagem "até então Brasília era a única capital no mundo que não tinha um museu de arqueologia”. Em posição de destaque no convite, estava a ponta de projétil resgatada na campanha de campo de Fogaça e Juliani, em 1997, e uma referência acadêmica de peso para o Brasil central em forma de homenagem, como se pode observar na Figura 1.

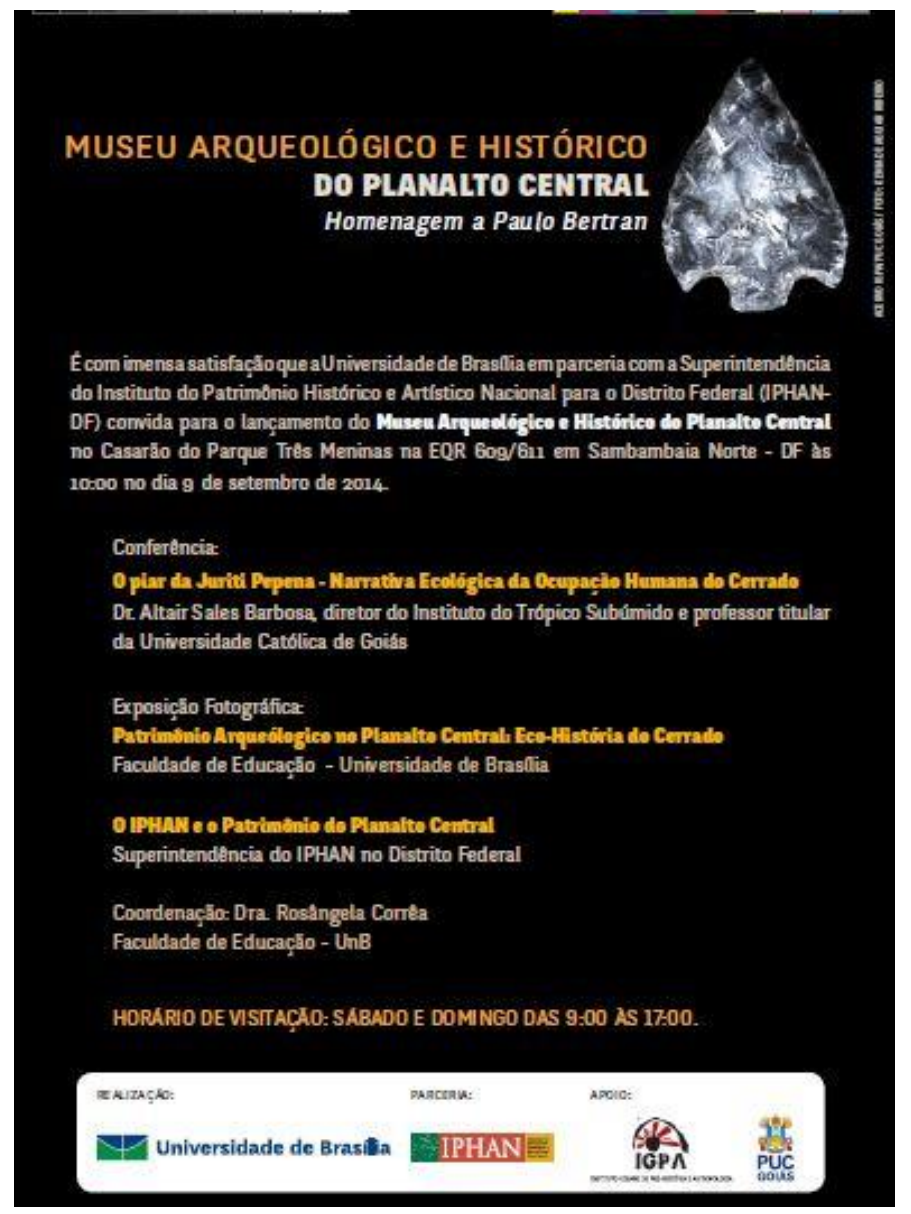

Figura 1: convite de lançamento do primeiro museu arqueológico do Distrito Federal 
Quando coletei dados primários para minha tese de doutorado, em 2008 e 2009, busquei entrevistar diferentes atores que pudessem abranger a compreensão pública acerca dos bens materiais identificados nas várias etapas de prospecção e salvamento arqueológico que ocorreram na área de proteção ambiental conhecida por ARIE $\mathrm{JK}^{4}$, onde existem sítios oficina líticos identificados que convencionei nomear de complexo arqueológico aqui. Foram 29 entrevistas individuais, semiabertas, que geraram mais de 20 horas de dados gravados. Conversei com indivíduos variados, pois buscava abranger um universo muito maior. Entrevistei todos os arqueólogos que ali coordenaram trabalhos de campo até aquele momento, bem como moradores imediatamente vizinhos aos sítios, das cidades-satélites do seu entorno e também moradores do Plano Piloto. Caracterizei seus vínculos institucionais, territoriais, e emocionais. Em nenhum momento, porém, visei criar comoção sobre preservação arqueológica. Nem introduzi assuntos relativos à proteção arqueológica. Ao final da pesquisa, percebi que a antiguidade dos sítios é o principal motivador para a criação de sentimentos de propriedade e de responsabilidade que pavimentam o longo caminho entre o passado e o presente daquele lugar.

À exceção dos colegas com os quais já mantinha contato, e para a minha surpresa, pois eu mantive interlocução bem mais concreta com outros atores, foi com o último entrevistado que construí uma relação de interação mais longínqua. E foi este ator, que sem o meu incentivo, quem definitivamente abraçou a ideia de apropriação do patrimônio arqueológico. Ele se chama Davi Silva Fagundes, naquela época me foi indicado por ser professor de História em uma escola pública de Samambaia e extremamente envolvido com preservação ambiental no Distrito Federal. Como para muitos dos atores entrevistados, para o professor Davi a ARIE JK já detinha um caráter significativo por sua importância hídrica e ambiental, e a arqueologia aparecia em segundo plano. Nos anos seguintes, eu acompanhei o início de uma jornada sem precedentes de um cidadão que estava engajado na causa arqueológica, e que buscou todos os mecanismos institucionais para assegurar a preservação não apenas da ARIE JK, mas do Distrito Federal como um todo.

Temos mantido contato desde então, e em muitos momentos tive que assumir 0 papel frustrante de alertá-lo para a enorme dificuldade em se iniciar um novo projeto arqueológico ali. Em nossos diálogos, optava por esconder minhas previsões pessimistas sobre a iminente destruição daqueles patrimônios em detrimento da pressão imobiliária e da própria pressão desenvolvimentista com a qual temos convivido nas últimas décadas. Meus caminhos levaram-me para longe do Distrito Federal, envolvi-me com outros temas de

\footnotetext{
${ }^{4}$ Área de Relevante Interesse Ecológico Juscelino Kubitschek.
} 
investigação, mas nunca deixei de me sentir responsável pela semente que plantei involuntariamente sob-responsabilidade de um ator extremamente proativo e envolvido na causa ambiental. Produzi uma síntese em português sobre a arqueologia na ARIE JK, a pedido do professor Davi (GODOY, 2014), e tenho tido o privilégio de compartilhar do cotidiano daquela realidade através das mensagens eletrônicas que trocamos.

Houve um silenciamento depois do convite de lançamento do museu, e no ano seguinte, em 2015, eu programei uma visita e negociei uma nova entrevista com ele. Encontrei o lugar onde seria o museu sem vestígios da sua existência, acompanhado de uma enorme apatia das instituições envolvidas quanto ao andamento da proposta. Nessa nova entrevista, perguntei quais os passos que foram tomados para a criação do museu:

Preocupados com as questões de ocupação irregular do solo na
ARIE-JK, montamos a Comissão Permanente da Agenda 21 de
Taguatinga, em 2011 , e realizamos vários encaminhamentos ao
Governo do Distrito Federal, com a indicação para a formação do
10 Museu Arqueológico do Distrito Federal no Parque Três Meninas
- Samambaia, para todos os Deputados Distritais da Câmara
Legislativa do Distrito Federal, IPHAN Regional do Distrito Federal
aos cuidados da Dra Maria Clara, Secretaria do Meio Ambiente do
Distrito Federal, Ministério Público do Distrito Federal e Territórios,
Arquivo Público do Distrito Federal, ressalto este ente público que
não possuía os arquivos de escavação dos Sítios da ARIE-JK, e
que foram entregues por mim, e figuro no Arquivo Público do DF
como depositário fiel dos arquivos de escavação dos Sítios da
ARIE-JK.

Esta estória não tem conclusão, portanto não posso classificar como uma tentativa fracassada. Os atores envolvidos, encabeçados pelo professor Davi, demonstraram interesse em efetivar a restituição da coleção arqueológica. Tanto o Instituto Goiano de PréHistória e Antropologia (IGPA/PUC-GO) quanto o IPHAN, atualmente responsáveis pela salvaguarda das coleções, concordavam com a ação desde que todos os requisitos necessários fossem cumpridos. Afinal, o que impediu a efetivação da proposta? Segundo Davi, foi a inércia do poder público; ele culpou o Governo do Distrito Federal. Neste caso, a articulação política entre arqueólogos, gestores e público foi ineficaz frente à dependência do estado em promover a ação. A restituição seria possível, e era uma demanda social, mas esbarrou nos meandros do governo desinteressado econômica, política e socialmente na promoção de uma instituição necessária, que seria um marco para o Distrito Federal e que certamente beneficiaria tanto a Arqueologia quanto a Museologia brasileiras perante o ineditismo da proposta. Talvez devêssemos rever as estratégias de colaboração e de publicidade da arqueologia; nosso passado precisa ser compreendido como relevante e interessante não apenas para o grande publico, mas para os governantes.

\begin{tabular}{|l|l|l|l|l|l|l}
\hline (C) Rev. Arqueologia Pública & Campinas, SP & v.11 & n.2 & p. 110 & Novembro/2017 & ISSN 2237-8294
\end{tabular} 


\section{CONSIDERAÇÕES FINAIS}

A mediação entre representações do passado e seu legado para o futuro nunca esteve tão ancorada nas construções do presente. Hoje, a função dos museus não pode se restringir somente à salvaguarda de artefatos, desse modo eles correm o risco de reproduzir ações hegemônicas centradas na coleta e pesquisa de materiais. Com a finalidade de romper com tais práticas, os museus devem tornar-se fóruns de negociação, cujo enfoque está na apropriação dos objetos pelos sujeitos aos quais pertencem.

O debate acerca das formas de colaboração na arqueologia é importante e inclui a problemática da salvaguarda patrimonial. No entanto, o museu também assume outras facetas na atualidade, que, em consonância com esta arqueologia descolonizante que desponta como imediata no século XXI, só tem a ganhar. As novas formas de musealização podem potencializar o estabelecimento de parcerias para a manutenção dos artefatos no local de origem, para então engendrar o sentido coletivo da comunidade e gerar benefícios para o desenvolvimento social da região, e para que os sujeitos reconheçam tais patrimônios enquanto produtos do fazer social e de valorização cultural.

Trouxemos um exemplo peculiar para incentivar o debate amplo. Podemos denominar colaboração quando apenas poucos indivíduos assumem o protagonismo da ação? A restituição e a repatriação de coleções arqueológicas podem ser consideradas como o resultado de uma arqueologia mais democrática? A restituição de bens arqueológicos ou a sua manutenção no local de origem não são práticas corriqueiras da realidade brasileira. Em contrapartida, desafio o leitor a discordar de ambas enquanto uma demanda social recorrente, especialmente nos locais mais isolados. A criação de novas instituições museais pode parecer uma luz no fim do túnel tanto para os públicos conscientes de sua propriedade quanto para gestores e arqueólogos que hoje se ocupam de encontrar soluções para o atual saturamento das reservas técnicas. Trata-se de mais uma dessas ações que na prática esbarram em meandros mais difíceis de serem resolvidos do que a conjugação de interesses e na parceria entre instituições e sociedade civil.

O estudo de caso apresentado demonstrou que por meio da presença de um interlocutor, um legítimo stakeholder que em nada se assemelha aos modelos que encontramos na bibliografia, motivou o debate multivocal sobre a implantação de uma instituição museológica capaz de salvaguardar e expor as coleções pré-históricas daquele passado tão distante dele mesmo. Um passado que tem sido reapropriado de uma maneira simbólica e que reflete a demanda de tantos grupos diversos na defesa de sua soberania. 


\section{REFERÊNCIAS BIBLIOGRÁFICAS}

ANDRADE LIMA, T. A Arqueologia na Construção da Identidade Nacional: uma disciplina no fio da navalha. Canindé, n. 10, p. 11-26. 2007.

ATALAY, S. 'We don't talk about Çatalhöyük, we live it': sustainable archaeological practice through community-based participatory research. World Archaeology, v. 42, n. 3, p. 418429. 2010.

BARBOSA, M. D. O.; COSTA, D. M. Costa. Relatório final do Projeto de Resgate e Monitoramento do Patrimônio Arqueológico da Área Diretamente Afetada pela Implantação do Interceptor e Emissário de Esgotos do Sistema Melchior, nos municípios de Taguatinga, Ceilândia e Samambaia - DF. IGPA e Fundação Aroeira/PUC-GO. Goiânia. 2005.

FERREIRA, C. Restituição dos bens culturais retirados no contexto do colonialismo: instrumento de desenvolvimento e de diálogo intercultural. Cadernos de Sociomuseologia, v. 47 , n. 3, p. 109-129. 2014.

FOGAÇA, E.; JULIANI, L. J. C. O. Programa de Avaliação de 1997. Potencial Arqueológico e Resgate dos Sítios DF-PA-11 a DF-PA-15. 1a Fase: Avaliação do potencial arqueológico do sítio DF-PA-11 e Avaliação do potencial informativo da coleção lítica recuperada no sítio DF-PA-11 (Taguatinga - DF). IPHAN, 14 Coordenadoria Regional. Brasília. 1997.

GODOY, R. D. Relatório da Equipe de Gestão. Relatório Parcial do Projeto de Resgate do Patrimônio Arqueológico da Área Diretamente Afetada pela Implantação do Interceptor e Emisário de Esgotos do Sistema Melchior. Goiânia: IGPA 2005.

Assessing Heritage Values: Public Archaeology in Brasília. Saarbrüchen: Lambert Academic Publishing. 2012. 252 p.

A Arqueologia na ARIE JK em Primeira Pessoa: seu potencial e a eterna preocupação com a sua preservação. Material não publicado produzido por demanda local. Brasília. 2014.

GREEN, L.; GREEN D. R. G.; NEVES, E. G. Indigenous Knowledge and Archaeological Science: the challenges of public archaeology in the Área Indígena do Uaçá. In: GNECCO, C.; AYALA, P. (Eds.). Indigenous Peoples and Archaeology in Latin America. Walnut Creek: Left Coast Press, p. 179-200, 2011.

LEITE, R. A. O. Difusão da ciência moderna em instituições de ciência e tecnologia: 0 Museu Paraense Emílio Goeldi. Belém: Museu Paraense Emílio Goeldi. 1993.

LIEBMAN, M. The Intersections of Archaeology and Postcolonial Studies. In: LIEBMAN, M.; RIZVI, U. Z. (Eds.). Archaeology and the Postcolonial Critique. Londres: Altamira Press/Rowman \& Littlefiled Publishers, p. 1-20, 2008.

\begin{tabular}{|l|l|l|l|l|l|l|}
\hline (C) Rev. Arqueologia Pública & Campinas, SP & v.11 & n.2 & p. 112 & Novembro/2017 & ISSN 2237-8294
\end{tabular} 
MELLO, P. J. C.; FOGAÇA, E. Projeto para Levantamento e Salvamento Arqueológicos na Área a ser Afetada pela Futura Implantação da Ligação Viária CeilândiaSamambaia (DF) - relatório parcial. IGPA and Fundação Aroeira/PUC-GO. Goiânia 2007

MERRIMAN, N. Introduction: diversity and dissonance in public archaeology. In: N. Merriman (Ed.). Public Archaeology. London: Routledge, p. 1-17, 2004.

MILLER, E. T. Avaliação do potencial arqueológico da área de expansão de Taguatinga/Ceilândia. ENGEA. Brasília. 1993.

SALADINO, A. IPHAN, arqueólogos e Patrimônio Arqueológico Brasileiro: um breve panorama. Revista de Arqueologia - SAB, v.27, n.1, p. 39-58. 2014.

SANTOS, M. E. V. M. D. Cidadania, conhecimento, ciência e educação CTS. Rumo a "novas" dimensões epistemológicas. Revista CTS, Buenos Aires. Disponível em: $<$ http://www.revistacts.net/volumen-2-numero-6/50-dossier/117-cidadaniaconhecimentociencia-e-educacao-cts-rumo-a-novas-dimensoesepistemologicas >, v. 2, n. 6, Acessado em: 16/06/2017, p. 137-157. 2005.

SUPERNANT, K. Special Forum on International Collaborations. The SAA Archaeological Record: Society for American Archaeology. 12: 28-50 p. 2012.

TELLES, M. A.; CASTRO, J. C. A. D. Relatório Final de Levantamento Arqueológico e Cultural da ADA Pela Construção do Centro Metropolitano de Taguatinga-DF. Griphus Consultoria Ltda. Goiânia: 2010.

VIANA, S. A. Instrumentos fora de seus contextos de produção - instrumentos líticos planoconvexos provenientes de sítios lito cerâmicos do estado de Mato Grosso. Revista Habitus, v. 9 , n. 1, p. 101-131. 2011. 